\title{
NICHOLS, Tom. The death of expertise: the campaign against established knowledge and why it matters. New York: Oxford University Press, 2017. 252 p.
}

\section{Luiz Gustavo Bonatto Rufino}

Brasil. Universidade Estadual Paulista. Doutor em Ciências da Motricidade pela Universidade Estadual Paulista (Unesp Rio Claro). Mestre em Desenvolvimento Humano e Tecnologias. ID ORCID: https://orcid.org/0000-0003-2567-9104.E-mail:gustavo_rufino_6@hotmail.com

A desvalorização dos conhecimentos e do alcance de parte da produção científica são evidências de que vivemos em uma realidade de culto à ignorância? Qual a importância da formação desenvolvida nas universidades? Qual o papel do jornalismo, da internet e das redes sociais nesse cenário? Em suma: vivemos a morte da expertise e do conhecimento profissional? Essas indagações permitem problematizar parte da conjuntura atual. Um desses aspectos se refere à relação entre profissionais e cidadãos nas sociedades democráticas. De um lado, os especialistas podem assumir posturas arrogantes e autoritárias, centradas no elitismo e no enclausuramento do campo acadêmico. De outro, cidadãos, usualmente considerados "leigos", têm assumido posturas e opiniões baseadas em crenças pouco articuladas com evidências científicas, propagando preconceitos, incompreensões, erros e até mesmo a própria negação do conhecimento.

Ora, vivemos em um momento cuja legitimação perpassa a desvalorização dos conhecimentos historicamente estabelecidos. Essa campanha contra a expertise se constitui como eixo articulador de boa parte das narrativas dos agentes que detêm o monopólio do poder. É com essa afirmação que 
o autor Tom Nichols inicia a construção de seu livro The death of expertise: the campaign against established knowledge and why it matters ${ }^{1}$. Para o autor, a alcunha dessa expressão não se refere apenas à negação do conhecimento existente, mas também à rejeição da ciência, da racionalidade e do senso crítico, fundamentos da civilização moderna. Exemplos são inúmeros, tais como as campanhas contra vacinação presentes em diversas localidades, visões que reforçam a ideia de que a Terra seja plana ou que buscam consolidar preconceitos étnicos, raciais etc. a partir de pressupostos científicos, entre diversos outros. No bojo dessa problemática, o autor elege para análise o papel dos especialistas e suas relações nas sociedades democráticas, particularmente nos Estados Unidos da América (EUA).

Nichols é professor universitário no US Naval War College e na Harvard Extesion School. Seu foco de atuação está nas relações internacionais, tendo se especializado no contexto histórico da Rússia. É também especialista em estudos de armas nucleares e nas relações de Estado e segurança nacional. Além de professor e escritor, atuou como conselheiro de políticos mediante questões vinculadas às relações internacionais do governo norte-americano. Apesar de conservador, é um dos mais ferrenhos críticos da política de Estado de Donald Trump. Esse contexto foi um elemento desencadeador da obra aqui tratada, apresentando contundentes críticas às relações políticas atuais nos EUA. Apesar de concentrar sua análise nesse país, é possível realizar uma série de paralelos com outras nações que enfrentam os mesmos problemas, uma vez que a ascensão de políticas neoliberais e do radicalismo de certos governos conservadores e de extrema direita tem sido uma das tônicas mais evidentes no campo político nos últimos tempos.

Apesar de não ser um tema inovador, a interpretação dada pelo autor e seus exemplos práticos, bem como os aspectos didáticos de sua escrita, sem contar sua capacidade argumentativa, fazem que o livro seja considerado como portador

\footnotetext{
Em tradução literal: A morte da expertise: a campanha contra o conhecimento estabelecido e por que isso importa. O livro ainda não foi publicado no Brasil, havendo apenas uma tradução em Portugal. O termo expertise se refere à perícia profissional, isto é, à profundidade e ao domínio de um conjunto de saberes de uma dada área de conhecimento. Alguns referenciais o relacionam com a ideia de "competência profissional". Optou-se pela manutenção do termo expertise porque compreende-se que ele abarca essa dimensão ligada à ideia de competência, domínio de habilidades, perícia, capacidade e conhecimento.
} 
de uma temática de grande relevância. Para Nichols, se a expertise não está morta, ela ao menos está ameaçada. Essas ameaças advêm de diferentes origens: da universidade, da internet, do campo político, do jornalismo e assim por diante. Em suma, o texto analisa a tensão que permeia a relação com o conhecimento nas sociedades democráticas.

Para Schön (1983), a crise da expertise e da competência profissional tem sua origem a partir do processo de perda de credibilidade dos conhecimentose dos julgamentos realizados pelos membros das profissões. Tardif (2012) ressalta que as profissões têm apresentado processos de "crise da perícia profissional" à medida que os dilemas apresentados no trabalho não encontram respaldo nos conhecimentos baseados na racionalidade técnica e instrumental. Essa perda de confiança no papel dos especialistas se deu por diversas razões, como pelas condutas pouco éticas que acabaram depreciando a confiança da sociedade em parte dos profissionais.

Segundo Freidson (2009), a expertise, composta pelas experiências, competências e conhecimentos especializados, é o elemento de maior importância, ao legitimar a ação profissional. Para o autor, a expertise se baseia no conhecimento adquirido pela formação, fundamentado pela ciência e legitimado socialmente. Questionar a competência profissional acaba por contrariar os conhecimentos científicos que balizam o pensamento.

Em sua obra, Tom Nichols assevera que o contexto democrático corre perigo, pois não se valorizam mais as opiniões e a competência dos especialistas em suas áreas de conhecimento. Ainda mais agravante: parte-se do pressuposto de que dar ouvido e valorizar a opinião de todos seja um dos pilares da democracia. Para o autor, democracia se refere a uma condição de equidade política: "uma pessoa, um voto". Todavia, quando se compreende que o pensamento democrático deve valorizar a opinião de todos, há uma inversão, na medida em que compreensões equivocadas, fake news e uma crescente valorização de "achismos" e de opiniões destituídas de fundamentação passam a estar presentes. Se por um lado o autor clama pela valorização dos especialistas, ele também compreende que nem sempre tais profissionais contribuíram com as sociedades. 
Tal compreensão se coaduna com análises semelhantes, a exemplo das obras de Empoli (2019) e de Levitsky e Ziblatt (2018). Ganha relevo a relação do conhecimento com o campo político e a inversão de paradigmas presentes atualmente, em que os políticos têm apresentado certo afastamento de conselhos de especialistas, indo na contramão de boa parte da história da política norte-americana.

Para dar cabo a essa empreitada, o autor organizou a obra em seis capítulos. O primeiro representa a relação entre especialistas e cidadãos no mundo atual. O segundo se refere ao processo de conversação e a como tal diálogo tem se tornado exaustivo. $O$ terceiro tece uma crítica à formação acadêmica e à relação de clientelismo presente nas universidades. O quarto critica a internet e o ilimitado acesso à informação. $\mathrm{O}$ quinto se refere às novas condutas jornalísticas e sua perda de fundamentação. O sexto e último capítulo traça uma análise sobre os erros e equívocos cometidos pelos profissionais. Ainda compõem a obra o prefácio (escrito pelo próprio autor), a introdução (que busca problematizar a conceituação sobre a "morte da expertise" e sua relação com diferentes campos, especialmente na política) e as conclusões, nas quais o autor aprofunda as análises sobre o conceito de democracia e apresenta algumas proposições e recomendações.

No primeiro capítulo, "Especialistas e cidadãos", Nichols discute a noção de expertise e realiza um resgate histórico da relação entre especialistas e leigos, reforçando que não se trata de algo novo, apesar de atualmente estar envolto em novas representações. Ele explicita que, a despeito dos problemas, quando deparamos com decisões complexas devemos optar pelas orientações dos especialistas ("no caso de uma cirurgia complicada, você escolheria um médico especialista ou um cidadão leigo que sabe dar palpites?”, pergunta o autor). Ainda, Nichols aponta que os ataques ao conhecimento têm levado à conviç̧ão de que qualquer um que frequente fóruns de internet seja tão inteligente e capaz como um perito para discutir determinado tema.

No segundo capítulo, intitulado "Como as conversações se tornaram exaustivas", o autor depara com os problemas de diálogo no mundo contemporâneo. Mais especificamente, há a crítica acerca das barreiras para o 
diálogo e como as pessoas no século XXI buscam arguir por meio do "viés de confirmação"2, utilizando-se de argumentos que se vinculam às suas crenças, bem como negando os que contradizem seu ponto de vista (independentemente da veracidade dessas argumentações), fazendo que o diálogo se torne inviável e as discordâncias se pareçam com insultos pessoais.

O terceiro capítulo é denominado "Ensino superior: o cliente está sempre certo" e traz uma crítica ferrenha ao processo de ensino em nível superior nos EUA, mesmo nas universidades mais reconhecidas. Critica-se a relação de clientelismo presente na formação universitária e o desprezo pela ciência. Essa abordagem de o "cliente estar sempre com a razão" é lesiva para a construção do senso crítico, pois valoriza-se mais o dinheiro do que a formação acadêmica alicerçada no conhecimento científico. Os resultados dessa configuração apresentam implicações lesivas para a morte da expertise.

No quarto capítulo, “Deixa eu dar um 'Google’ nisso para você: como a informação ilimitada está nos deixando mais estúpidos", o autor afirma que a revolução tecnológica não explica todas as causas da "morte da expertise", mas apresenta sua relevância. Para Nichols, a internet se tornou mais uma plataforma de ataque ao conhecimento estabelecido do que de defesa dele. Assim, ele clama que passamos por tempos perigosos, uma vez que nunca tivemos tanto acesso às informações e, ainda assim, estamos resistentes a aprender e reconhecer nossas limitações.

Nessa conjuntura, em sociedades livres os jornalistas deveriam, entre outras coisas, se portar como importantes juízes na curadoria das informações. Todavia, com um jornalismo baseado mais no entretenimento do que no acesso crítico à informação e com o fenômeno provocado pelas fake news, há graves problemas nessa relação. Essa é a análise promovida pelo capítulo cinco, cujo título é "O 'novo' novo jornalismo".

O capítulo seis apresenta uma ponderação importante. Intitulado "Quando os especialistas erram”, nele o autor apresenta inúmeras considerações e exemplos acerca dos possíveis erros ocasionados pelos especialistas, os quais reforçam posturas que promovem a "morte da expertise". Tais equívocos vão desde visões

2 Do termo original em inglês: "confirmation bias". 
fraudulentas até posturas bem-intencionadas, mas cobertas de arrogância e confiança exacerbada. Contudo, atualmente, utilizam-se os exemplos de erros dos especialistas como forma de generalização de suas posturas profissionais, ocasionando a crítica de seu papel na sociedade e, consequentemente, a desvalorização de sua competência e expertise.

Finalmente, as conclusões abordam a relação entre especialistas e democracia. $\mathrm{O}$ autor reforça seus argumentos apresentando que a visão de democracia não deve ser distorcida a ponto de permitir que as pessoas achem que todas as opiniões apresentam a mesma importância, seja qual for o domínio de cada um sobre dado tema. Para ele, as opiniões e crenças têm assumido papel maior do que os fatos e o conhecimento científico. O autor apresenta recomendações, tornando o texto propositivo, a exemplo da importância do exercício da humildade por parte dos especialistas, bem como a necessidade de diversificação de suas fontes de informação. Ele considera que os especialistas precisam ser menos cínicos para que a sociedade recupere a confiança neles. Ainda, para o autor, devemos procurar ser mais exigentes: verificar a veracidade das fontes e suas motivações políticas é uma condição sine qua non da atualidade.

Clamar que a democracia está em crise apresenta consonância com boa parte da literatura atual. Contudo o olhar oferecido pelo autor acerca da importância do conhecimento e da relação entre especialistas e cidadãos no mundo se mostra uma prioridade atualmente latente. Os exemplos claros e atuais e a contemporaneidade da temática fazem que a obra tenha relevância e contribua para compreendermos as contradições do mundo em que vivemos.

\section{REFERÊNCIAS BIBLIOGRÁFICAS}

1. EMPOLI, Giuliano Da. Os engenheiros do caos. Belo Horizonte: Vestígio, 2019.

2. LEVITSKY, Steven; ZIBLATT, Daniel. How democracies die. New York: Broadway Books, 2018. 
3. SCHÖN, Donald. The reflective practitioner: how professionals think in action. New York: Basic Books, 1983.

4. TARDIF, Maurice. Saberes docentes e formação profissional. Petrópolis: Vozes, 2012. 